\title{
A 60 GHz Planar Diplexer Based on Substrate Integrated Waveguide Technology
}

\author{
Nikolaos Athanasopoulos, Dimitrios Makris, and Konstantinos Voudouris \\ Wireless Communications and e-Applications Research Group, Technological Educational Institute of Athens, \\ Agion Spyridonos and Pallikaridi Street, 12210 Athens, Greece
}

Correspondence should be addressed to Nikolaos Athanasopoulos; nikathanaso@gmail.com

Received 16 September 2012; Revised 31 December 2012; Accepted 8 January 2013

Academic Editor: Egidio Ragonese

Copyright (C) 2013 Nikolaos Athanasopoulos et al. This is an open access article distributed under the Creative Commons Attribution License, which permits unrestricted use, distribution, and reproduction in any medium, provided the original work is properly cited.

\begin{abstract}
This paper presents a millimeter-wave, $60 \mathrm{GHz}$ frequency band planar diplexer based on substrate integrated waveguide (SIW) technology. Diplexer consists of a pair of 5th-order SIW bandpass channel filters with center frequencies at $59.8 \mathrm{GHz}$ and $62.2 \mathrm{GHz}$ providing $1.67 \%$ and $1.6 \%$ relative bandwidths, respectively. SIW-to-microstrip transitions at diplexer ports enable integration in a millimeter-wave transceiver front end. Measurements are in good agreement with electromagnetic simulation, reporting very good channel isolation, small return losses, and moderate insertion losses in the passbands. The proposed SIW planar diplexer is integrated into a millimeter-wave transceiver front end for $60 \mathrm{GHz}$ point-to-point multigigabit wireless backhaul applications, providing high isolation between transmit and receive channels.
\end{abstract}

\section{Introduction}

The deployment of millimeter-wave integration technologies is critical for the wireless systems evolution. A variety of applications have been recently proposed in the frequency range between $60 \mathrm{GHz}$ and $94 \mathrm{GHz}$ including wireless networks [1], automotive radars [2], imaging sensors [3], and biomedical devices [4]. These systems require cost-effective technologies suitable for mass production and high density integration techniques, combined with a low-cost fabrication process. Substrate Integrated Waveguide (SIW) technology [5-8] is a promising candidate for providing compact, flexible, and cost-effective millimeter-wave circuits and systems which preserve most of the advantages of the conventional metallic waveguides, namely, complete shielding, low loss, high-quality factor, and high power handling capability [9]. Most of the classical passive components have been implemented in SIW technology. This solution usually permits to obtain components with a substantial reduction in size; moreover, the losses are lower than in the corresponding microstrip devices especially in the millimeter-wave frequency range, and there are no radiation and packaging problems. In the literature, SIW filters have received a particular attention. Focusing on the $60 \mathrm{GHz}$ frequency band, in [10] a four-pole $60 \mathrm{GHz}$ SIW bandpass filter has been modeled, while in [11] a $60 \mathrm{GHz}$ SIW quasi-elliptic filter has been designed and fabricated.

The diplexer is one of the key components in a transceiver front end and greatly affects system's performance acting as channel separator. This becomes evident in the frequency division duplex systems where frequency separation between transmit and receive chains needs to be provided. Diplexer design is usually based on waveguide technology with excellent performance in terms of insertion loss and channelto-channel isolation [12-14]. However, the design suffers from disadvantages such as being bulky, costly, and difficult to fabricate. Moreover, it cannot be integrated with the rest of the millimeter-wave planar integrated circuits that the transceiver front end consists of. On the other hand, diplexer implementation in SIW provides a compact, costeffective solution preserving most of the advantages of the conventional metallic waveguides, while in parallel it enables the diplexer integration with the rest of the millimeterwave transceiver front-end components. In the literature, SIW planar diplexers operating at $5 \mathrm{GHz}$ and $25 \mathrm{GHz}$ have been proposed in $[15,16]$, respectively, while the generalized 


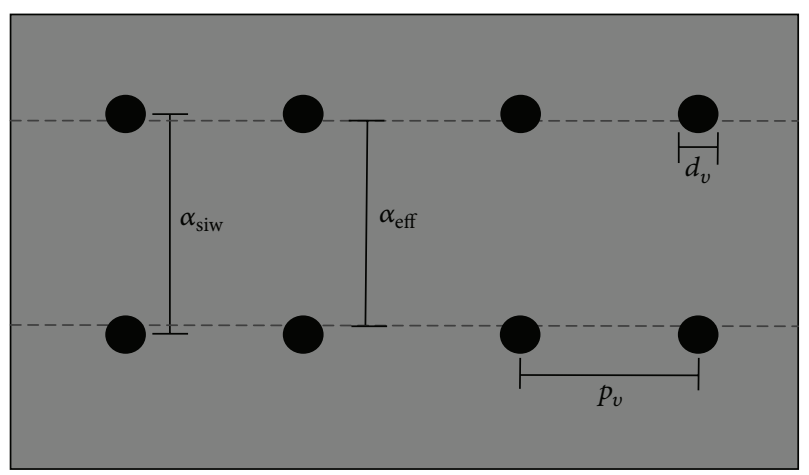

FIgURE 1: The SIW general structure.

$1 \mathrm{GHz}$ frequency band chebyshev SIW diplexer has been described in [17]. In [18] a $5 \mathrm{GHz}$ frequency band SIW diplexer loaded by complementary split-ring resonators has also been proposed.

This paper is focused on a $60 \mathrm{GHz}$ frequency band SIW planar diplexer that is integrated in a millimeter-wave transceiver front end operating in frequency division duplexing mode for point-to-point wireless backhaul applications. The proposed diplexer is composed by 5th-order SIW bandpass channel filters providing high channel-to-channel isolation. SIW-to-microstrip transitions provide diplexer integration with the transceiver front end. In [19], authors presented the design and modeling procedures of the 5th-order SIW bandpass filters with center frequencies at $59.8 \mathrm{GHz}$ and $62.2 \mathrm{GHz}$, providing $1 \mathrm{GHz}$ bandwidth. Electromagnetic simulation results reported very good performance in terms of passband insertion loss and return loss, as well as in terms of out-of-band rejection. Based on these results, authors in [20] provided an initial approach of a $60 \mathrm{GHz}$ SIW planar diplexer providing preliminary designs and electromagnetic simulation results. Diplexer design was further optimized and fabricated, and in this paper measurement results are provided and compared with simulation ones.

\section{The 60 GHz SIW General Structure}

SIW structure is fabricated by using two periodic rows of metallic vias connecting the top and bottom ground planes of a dielectric substrate. The top side of a general SIW structure is depicted in Figure 1.

SIW width, $\alpha_{\text {SIW }}$, is calculated based on the corresponding rectangular waveguide width, $\alpha$, as follow:

$$
\alpha_{\mathrm{SIW}}=\frac{\alpha}{\sqrt{\varepsilon_{r}}}
$$

where $\varepsilon_{r}$ is the substrate dielectric constant. The replacement of conductive walls by metallic vias leads to the variation of SIW structure width. The equivalent width is called effective width and depends on design parameters. According to [7], the SIW effective width, $\alpha_{\text {eff }}$, is given by

$$
\alpha_{\text {eff }}=\alpha_{\text {SIW }}-1.08 \cdot \frac{d_{v}^{2}}{p_{v}}+0.1 \cdot \frac{d_{v}^{2}}{\alpha_{\text {SIW }}} .
$$

Via diameter $d_{v}$ and pitch via $p_{v}$ should be appropriately set in order to ensure that there is no radiation leakage between metallic vias due to diffraction. In [21], the following design rules are given in order to avoid such effects:

$$
d_{v}=\frac{\lambda_{g}}{5}, \quad p_{v} \leq 2 \cdot d_{v}
$$

In this paper, dielectric substrate Rogers RT/duroid $5880\left(\varepsilon_{r}=\right.$ 2.2; $\tan \delta=0.0009$; dielectric thickness $h=0.508 \mathrm{~mm}$ ) is used. Taking into account that the $60 \mathrm{GHz}$ frequency band rectangular waveguide (WR-15) width is $\alpha=3.759 \mathrm{~mm}$ and applying (1)-(3), the SIW basic parameters for the $60 \mathrm{GHz}$ band are calculated and summarized in Table 1.

\section{The $60 \mathrm{GHz}$ SIW Planar Diplexer}

3.1. SIW Channel Filter Modeling. The diplexer consists of two bandpass channel filters with center frequencies at $59.8 \mathrm{GHz}$ (receive chain) and $62.2 \mathrm{GHz}$ (transmit chain), respectively. Channel filter bandwidth requirement is $1 \mathrm{GHz}$, and filter order is 5. Figure 2 depicts the 5th-order SIW bandpass filter model.

Filter modeling was presented by authors in [19], and it is based on the $n$-order IRIS waveguide bandpass filter analysis suggested in [22]. According to that, the equivalent circuit of an IRIS which is placed parallel to the electrical field is a shunt inductor. Waveguide cavity length $l_{i},(i=1, \ldots, n)$ and IRIS aperture width $d_{i}(i=1, \ldots, n+1)$ are calculated based upon filter specifications. The suggested analysis was suitably adjusted in [19], in order to calculate the corresponding $l_{i}$ and $d_{i}$ for the SIW bandpass channel filters. Given that the guided wavelength in the rectangular waveguide is

$$
\lambda_{g \mathrm{WG}}=\frac{\lambda_{0}}{\sqrt{1-\left(\lambda_{0} / 2 \alpha\right)^{2}}},
$$

where $\lambda_{0}$ is the free space wavelength, $\alpha$ is the rectangular waveguide width, and the guided wavelength in the SIW structure is given by

$$
\lambda_{\text {gSIW }}=\frac{\lambda_{\text {diel }}}{\sqrt{1-\left(\lambda_{\text {diel }} / 2 \alpha_{\text {eff }}\right)^{2}}}
$$

where $\alpha_{\text {eff }}$ is the SIW effective width and $\lambda_{\text {diel }}$ is given by

$$
\lambda_{\text {diel }}=\frac{\lambda_{0}}{\sqrt{\mu_{0} \varepsilon_{r}}} .
$$

Based on given filters' specifications and using (4)-(6), $l_{i}$ and $d_{i}$ were calculated. Design was performed using Ansoft HFSS v.12, while an optimization procedure was followed in order to meet the desired specifications. Simulation results reported that, for the transmit channel, filter center frequency was at $62.2 \mathrm{GHz}$ providing $1 \mathrm{GHz}$ bandwidth. Insertion loss was $1.5 \mathrm{~dB}$, while return loss was varying below $20 \mathrm{~dB}$ in the passband. Filter rejection at transmit channel, filter center frequency $(59.8 \mathrm{GHz})$ was $90 \mathrm{~dB}$. Concerning the receive channel filter, center frequency was at $59.8 \mathrm{GHz}$ with $1 \mathrm{GHz}$ 


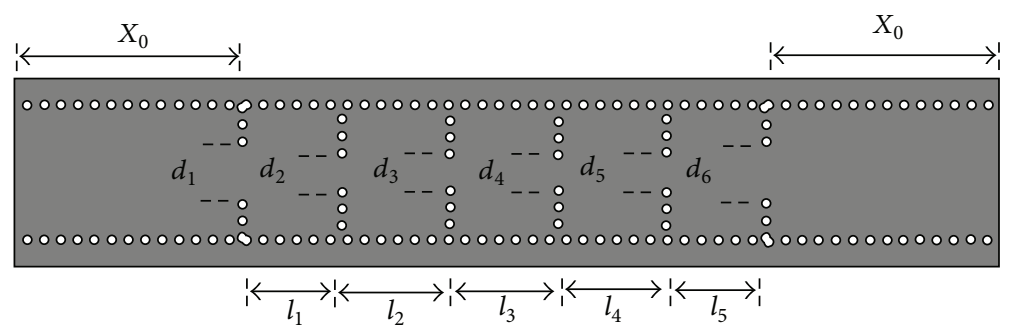

FIgURE 2: The 5th-order SIW bandpass channel filter model.

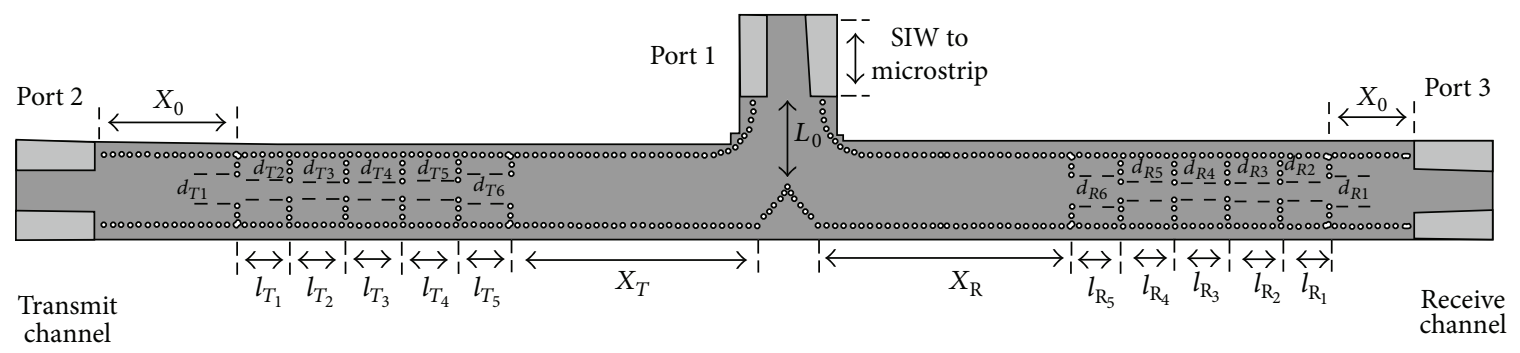

FIgURE 3: The SIW planar diplexer design model.

bandwidth. Insertion loss was about $2 \mathrm{~dB}$, while return loss was varying below $20 \mathrm{~dB}$ in the passband. Filter rejection at receive channel filter center frequency $(62.2 \mathrm{GHz})$ was $66 \mathrm{~dB}$.

\subsection{Diplexer Integration. In Figure 3, the SIW planar diplexer} model is presented.

Design parameters for channel filters $\left(l_{i}, i=1, \ldots, n\right.$, and $\left.d_{i}, i=1, \ldots, n+1\right)$ were calculated in [19]. Parameter $X_{0}$ represents the space length at the SIW channel filter ports before the edge cavities, and as it was observed during design procedure, it is a critical parameter for filter impendence matching. As it was shown in [20], authors initially set $X_{0}$ to be equal to $\lambda_{g s i w} / 2$. The optimization procedure proved that optimum performance in terms of input return loss was given when $X_{0}$ was precisely equal to $\lambda_{\text {gsiw }}$.

A SIW T-junction was designed in order to integrate the channel filters within diplexer and to ensure the minimum coupling between them. As it was presented in [20], the key for the T-junction design is to ensure TE10 mode propagation as well as incident electromagnetic waves at channel filters to be equal amplitude and in phase. Figure 4 shows the SIW T-junction as well as the HFSS simulation electric field distribution within the structure.

The transition from common port towards filter chains is based on mitering technique in order to reduce the reflections from transmit and receive ports. The first center via is placed at a distance $L_{0}$ from the diplexer common port. According to [20], distance $L_{0}$ is critical for common port performance in terms of input return loss. $L_{0}$ was initially set equal to SIW wavelength $\lambda_{\text {gSIW }}$, and based on tuning, the optimum value for $L_{0}$ was found. Parameters $X_{T}$ and $X_{R}$ represent the distance between the T-junction and the first cavity of the transmit and receive channel filters, respectively, and they were initially set equal to $2 \lambda_{\text {gsiw }}$. Optimization procedure provided values that corresponded to lower reflections in diplexer ports.

50 Ohm SIW-to-microstrip transitions were predicted for diplexer ports in order for the diplexer to be connected with test equipment during performance verification. As it can be seen in Figure 5, SIW-to-microstrip transition consists of one transmission line with dimensions $a_{1}$ and $w_{1}$ and one tapered line with dimensions $a_{2}$ and $w_{2}$.

The suitable SIW-to-microstrip transition design enables TE10 mode to be propagated into the SIW structure. The microstrip width, $w_{i}(i=1,2)$, is calculated based upon the following equation:

$$
w_{i}=\frac{Z_{k} \cdot h}{\sqrt{e_{\mathrm{ff}}} Z_{0}},
$$

where $Z_{k}$ is the free space impedance $\left(Z_{k}=376.8 \mathrm{Ohm}\right), h$ is dielectric substrate thickness provided in Table 1 , and $e_{\mathrm{ff}}$ that is effective permittivity of the dielectric substrate for $w>h$ is given by

$$
e_{\mathrm{ff}}=\varepsilon_{r} \text {. }
$$

A diplexer model without transitions was designed and simulated using HFSS in order to calculate SIW structure input impedance $Z_{0}$. Simulation gave $Z_{0}=48 \mathrm{Ohm}$ for all diplexer ports, and using (7), $w_{2}$ was computed. $Z_{0}=50 \mathrm{Ohm}$ was considered for the SMA connector, and using (7), $w_{1}$ was computed. 


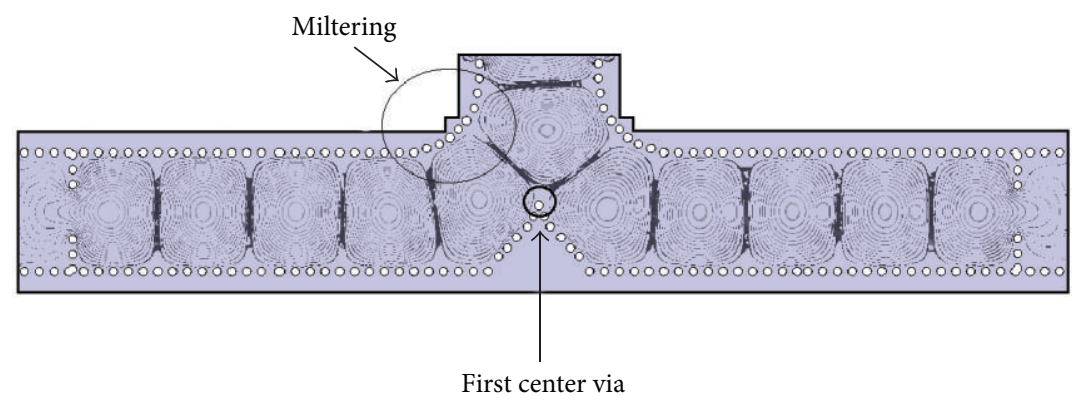

Figure 4: The electric field distribution within SIW T-junction.

TABLE 1: Summary of SIW design parameters at $60 \mathrm{GHz}$ frequency band.

\begin{tabular}{lccc}
\hline Parameter & Symbol & Value & Unit \\
\hline Dielectric substrate & & RT/duroid $5880\left(\varepsilon_{r}=2.2 ; \tan \delta=0.0009 ; h=0.508\right)$ & $\mathrm{mm}$ \\
Pitch via & $p_{v}$ & 0.35 & $\mathrm{~mm}$ \\
Via diameter & $d_{v}$ & 0.2 & $\mathrm{~mm}$ \\
SIW width & $\alpha_{\text {SIW }}$ & 2.8 & $\mathrm{~mm}$ \\
SIW effective width & $\alpha_{\text {eff }}$ & 2.678 & $\mathrm{~mm}$ \\
\hline
\end{tabular}

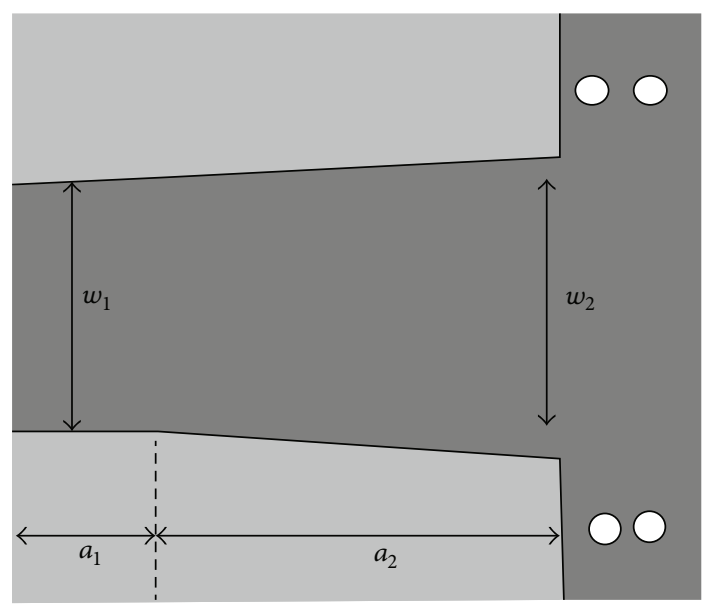

FIgURE 5: The SIW-to-microstrip transition model.

The total microstrip transition length $\left(a_{1}+a_{2}\right)$ is equal to one microstrip wavelength $\lambda_{g}$, where

$$
\lambda_{g}=\frac{\lambda_{0}}{\sqrt{\varepsilon_{r}}} .
$$

Optimization given for $a_{1}$ and $a_{2}$ is as follows:

$$
\alpha_{1}=\frac{\lambda_{g}}{4}, \quad \alpha_{2}=3 \cdot \frac{\lambda_{g}}{4} .
$$

In Table 2, all design parameters for SIW diplexer are summarized.

\section{Results}

The $60 \mathrm{GHz}$ SIW planar diplexer is depicted in Figure 6.

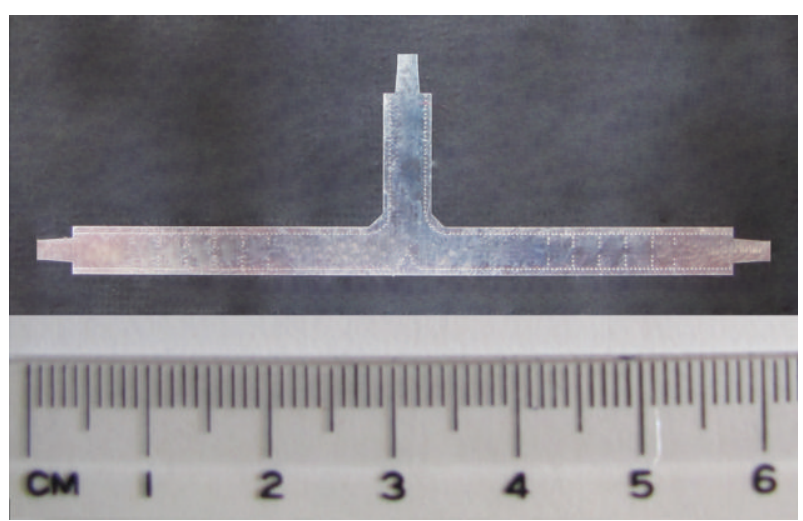

FIgURE 6: The $60 \mathrm{GHz}$ SIW planar diplexer.

Figure 7 shows diplexer performance in terms of common port return loss $\left(S_{11}\right)$ as well as in terms of channelto-channel isolation $\left(S_{23}\right)$. Both measurement and simulation results are provided, and as it can be seen, they are in good agreement. Common port return loss varies below $10 \mathrm{~dB}$ in the passbands, while channel-to-channel isolation varies below $60 \mathrm{~dB}$ in the whole frequency range.

Figure 8 shows transmit and receive ports' insertion loss $\left(S_{12}\right.$ and $S_{13}$, resp.). As it can be seen, there is a shift in the predefined center frequencies of the passbands, while the achieved relative bandwidths are $1.67 \%$ and $1.6 \%$, respectively. The observed frequency down shift, which is approximately $300 \mathrm{MHz}$, is caused by fabrication accuracy and tolerances of manufacture, parameters that introduce such effects especially in the millimeter-wave frequency band. Insertion loss is about $4 \mathrm{~dB}$ for both transmit and receive passbands. The transmit channel out-of-band rejection is $55 \mathrm{~dB}$ at $62.2 \mathrm{GHz}$, 
TABle 2: Summary of the $60 \mathrm{GHz}$ SIW planar diplexer design parameters.

\begin{tabular}{|c|c|c|c|c|c|c|c|c|c|c|c|c|c|}
\hline & & $\begin{array}{c}X_{0} \\
(\mathrm{~mm})\end{array}$ & $\begin{array}{c}l_{1} \\
(\mathrm{~mm})\end{array}$ & $\begin{array}{c}l_{2} \\
(\mathrm{~mm})\end{array}$ & $\begin{array}{c}l_{3} \\
(\mathrm{~mm})\end{array}$ & $\begin{array}{c}l_{4} \\
(\mathrm{~mm})\end{array}$ & $\begin{array}{c}l_{5} \\
(\mathrm{~mm})\end{array}$ & $\begin{array}{c}d_{1} \\
(\mathrm{~mm})\end{array}$ & $\begin{array}{c}d_{2} \\
(\mathrm{~mm})\end{array}$ & $\begin{array}{c}d_{3} \\
(\mathrm{~mm})\end{array}$ & $\begin{array}{c}d_{4} \\
(\mathrm{~mm})\end{array}$ & $\begin{array}{c}d_{5} \\
(\mathrm{~mm})\end{array}$ & $\begin{array}{c}d_{6} \\
(\mathrm{~mm})\end{array}$ \\
\hline \multirow{4}{*}{$\begin{array}{l}\text { Channel } \\
\text { filters }\end{array}$} & Receiver filter $(62.2 \mathrm{GHz})$ & 4.70 & 2.07 & 2.24 & 2.26 & 2.24 & 2.07 & 1.09 & 0.61 & 0.54 & 0.54 & 0.61 & 1.09 \\
\hline & Transmitter filter $(59.8 \mathrm{GHz})$ & 4.70 & 2.07 & 2.24 & 2.26 & 2.11 & 2.07 & 1.06 & 0.59 & 0.52 & 0.52 & 0.59 & 1.06 \\
\hline & & \multicolumn{3}{|c|}{$w_{1}(\mathrm{~mm})$} & \multicolumn{3}{|c|}{$w_{2}(\mathrm{~mm})$} & \multicolumn{3}{|c|}{$a_{1}(\mathrm{~mm})$} & \multicolumn{3}{|c|}{$a_{2}(\mathrm{~mm})$} \\
\hline & Receive port & & 1.57 & & & 1.92 & & & 0.8 & & & 2.4 & \\
\hline \multirow{3}{*}{$\begin{array}{l}\text { SIW-to-microstrip } \\
\text { transitions }\end{array}$} & Transmit port & & 1.57 & & & 1.92 & & & 0.8 & & & 2.4 & \\
\hline & Common port & & 1.57 & & & 1.92 & & & 0.8 & & & 2.4 & \\
\hline & & \multicolumn{4}{|c|}{$L_{0}(\mathrm{~mm})$} & \multicolumn{4}{|c|}{$X_{T}(\mathrm{~mm})$} & \multicolumn{4}{|c|}{$X_{R}(\mathrm{~mm})$} \\
\hline T-junction & & \multicolumn{3}{|c|}{3.55} & & \multicolumn{4}{|c|}{9.8} & \multicolumn{4}{|c|}{10.07} \\
\hline
\end{tabular}

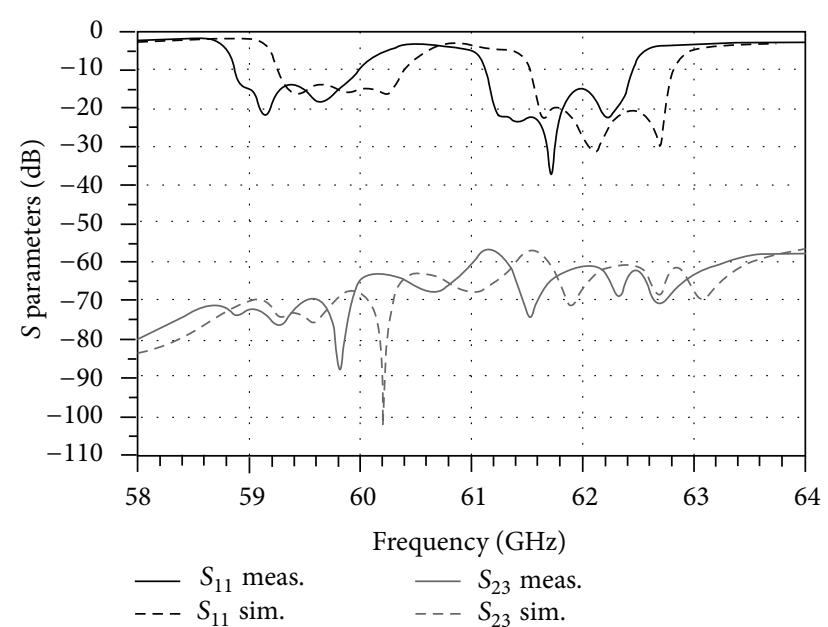

FIGURE 7: Diplexer performance in terms of common port return loss and channel-to-channel isolation.

while the receive channel out-of-band rejection is $58 \mathrm{~dB}$ at $59.8 \mathrm{GHz}$.

Finally, Figure 9 shows diplexer performance in terms of transmit and receive ports' return loss $\left(S_{22}\right.$ and $S_{33}$, resp.). As it can be seen, $S_{22}$ and $S_{33}$ vary below $10 \mathrm{~dB}$ in transmit and receive passbands, respectively.

\section{Conclusion}

The design, development, and fabrication of a $60 \mathrm{GHz}$, millimeter-wave planar diplexer based on the substrate integrated waveguide technology are presented in this paper. Measurement results report very good performance in terms of insertion loss in the channel filters passbands and return loss in all diplexer ports' bands. The high channel filter bandwidth in combination with the achieved high out-ofband rejection and high channel-to-channel isolation enables the usage of the proposed diplexer as channel separator in high bandwidth millimeter wave transceiver front ends.

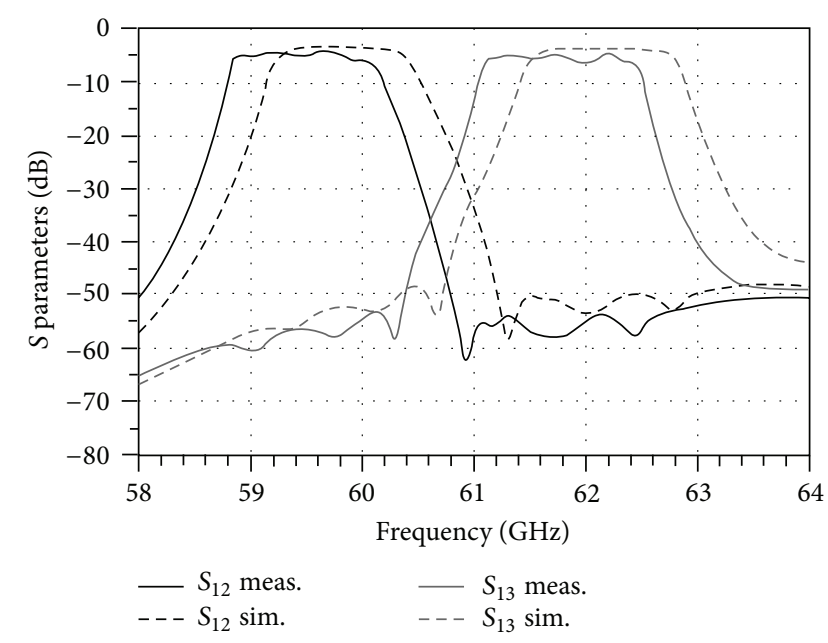

FIgURE 8: Diplexer performance in terms of receive and transmit ports' insertion loss.

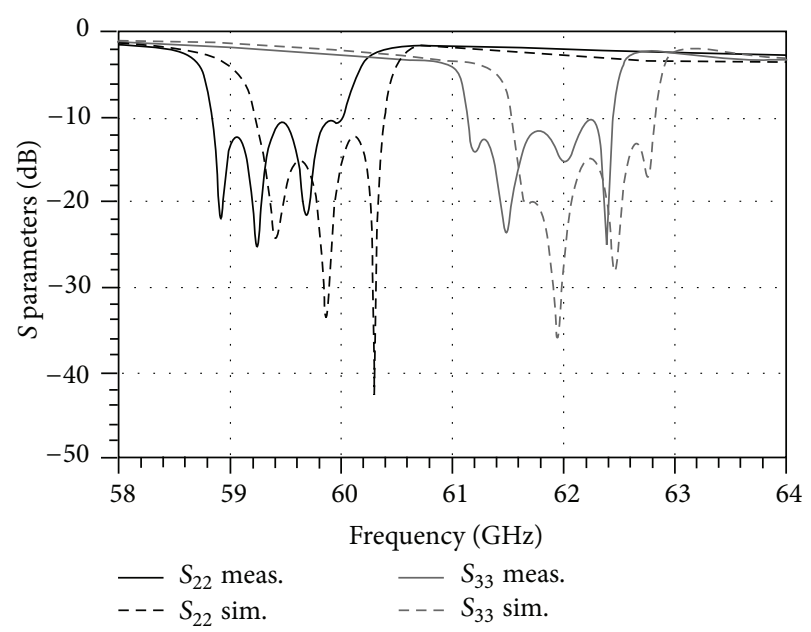

FIGURE 9: Diplexer performance in terms of receive and transmit ports' return loss. 


\section{Acknowledgment}

This work is partially funded by the EU Regional Fund within the concept of NexGenMilliWave project (Contract MICRO2-53).

\section{References}

[1] R. C. Daniels and R. W. Heath, " $60 \mathrm{GHz}$ wireless communications: emerging requirements and design recommendations," IEEE Vehicular Technology Magazine, vol. 2, no. 3, pp. 41-50, 2007.

[2] W. J. Fleming, "New automotive sensors-a review," IEEE Sensors Journal, vol. 8, no. 11, pp. 1900-1921, 2008.

[3] L. Yujiri, M. Shoucri, and P. Moffa, "Passive millimeter wave imaging," IEEE Microwave Magazine, vol. 4, no. 3, pp. 39-50, 2003.

[4] K. Mizuno, Y. Wagatsuma, H. Warashina et al., "Millimeterwave imaging technologies and their applications," in Proceedings of the 8th IEEE International Vacuum Electronics Conference (IVEC '07), pp. 13-14, May 2007.

[5] U. Hiroshi, T. Takeshi, and M. Fujil, "Development of a 'laminated waveguide"' IEEE Transactions on Microwave Theory and Techniques, vol. 46, no. 12, pp. 2438-2443, 1998.

[6] D. Deslandes and K. Wu, "Single-substrate integration technique of planar circuits and waveguide filters," IEEE Transactions on Microwave Theory and Techniques, vol. 51, no. 2, pp. 593-596, 2003.

[7] $\mathrm{F} . \mathrm{Xu}$ and $\mathrm{K}$. Wu, "Guided-wave and leakage characteristics of substrate integrated waveguide," IEEE Transactions on Microwave Theory and Techniques, vol. 53, no. 1, pp. 66-72, 2005.

[8] D. Deslandes and K. Wu, "Accurate modeling, wave mechanisms, and design considerations of a substrate integrated waveguide," IEEE Transactions on Microwave Theory and Techniques, vol. 54, no. 6, pp. 2516-2526, 2006.

[9] M. Bozzi, L. Perregrini, K. Wu, and P. Arcioni, "Current and future research trends in substrate integrated waveguide technology," Radioengineering, vol. 18, no. 2, pp. 201-209, 2009.

[10] F. Mira, A. A. San Blast, V. E. Boria, and B. Gimeno, "Fast and accurate analysis and design of Substrate Integrated Waveguide (SIW) filters," in Proceedings of the 37th European Microwave Conference (EUMC '07), pp. 170-173, October 2007.

[11] G. H. Lee, C. S. Yoo, J. G. Yook, and J. C. Kim, "SIW (Substrate Integrated Waveguide) quasi-elliptic filter based on LTCC for $60-\mathrm{GHz}$ application," in Proceedings of the 4th European Microwave Integrated Circuits Conference (EuMIC '09), pp. 204207, October 2009.

[12] A. Morini and T. Rozzi, "Analysis of compact E-plane diplexers in rectangular waveguide," IEEE Transactions on Microwave Theory and Techniques, vol. 43, no. 8, pp. 1834-1839, 1995.

[13] J. Dittloff and F. Arndt, "Computer-aided design of slit-coupled H-plane T-junction diplexers with E-plane metal-insert filters," IEEE Transactions on Microwave Theory and Techniques, vol. 36, no. 12, pp. 1833-1840, 1988.

[14] E. Ofli, R. Vahldieck, and S. Amari, "Novel E-plane filters and diplexers with elliptic response for millimeter-wave applications," IEEE Transactions on Microwave Theory and Techniques, vol. 53, no. 3, pp. 843-851, 2005.

[15] Z. C. Hao, W. Hong, X. P. Chen, J. X. Chen, and K. Wu, "Planar diplexer for microwave integrated circuits," Microwaves, Antennas and Propagation, IEE Proceedings, vol. 152, no. 6, pp. 455-459, 2005.
[16] H. J. Tang, W. Hong, J. X. Chen, G. Q. Luo, and K. Wu, "Development of millimeter-wave planar diplexers based on complementary characters of dual-mode substrate integrated waveguide filters with circular and elliptic cavities," IEEE Transactions on Microwave Theory and Techniques, vol. 55, no. 4, pp. 776-782, 2007.

[17] S. H. Han, X. L. Wang, Y. Fan, Z. Q. Yang, and Z. N. He, “The generalized chebyshev substrate integrated waveguide diplexer," Progress in Electromagnetics Research, vol. 73, pp. 29-38, 2007.

[18] Y. Dong and T. Itoh, "Substrate integrated waveguide loaded by complementary split-ring resonators for miniaturized diplexer design," IEEE Microwave and Wireless Components Letters, vol. 21, no. 1, pp. 10-12, 2011.

[19] N. Athanasopoulos, D. Makris, and K. Voudouris, "5th order millimeter-wave substrate integrated waveguide band pass filters," in Proceedings of the IEEE International Conference on Electromagnetics in Advanced Applications (ICEAA '11), pp. 98101, September 2011.

[20] N. Athanasopoulos, D. Makris, and K. Voudouris, "Development of a $60 \mathrm{GHz}$ Substrate Integrated Waveguide planar diplexer," in Proceedings of the IEEE-MTT-S International Microwave Workshop Series on Millimeter Wave Integration Technologies, pp. 691-694, 2011.

[21] D. Deslandes and K. Wu, "Design consideration and performance analysis of Substrate Integrated Waveguide components," in Proceedings of the 32nd European Microwave Conference, pp. 1-4, September 2002.

[22] G. Matthaei, L. Young, and E. M. T. Jones, Microwave Filters, Impendence-Matching Networks, and Coupling Structures, Artech House, Norwood, NJ, USA, 1980. 

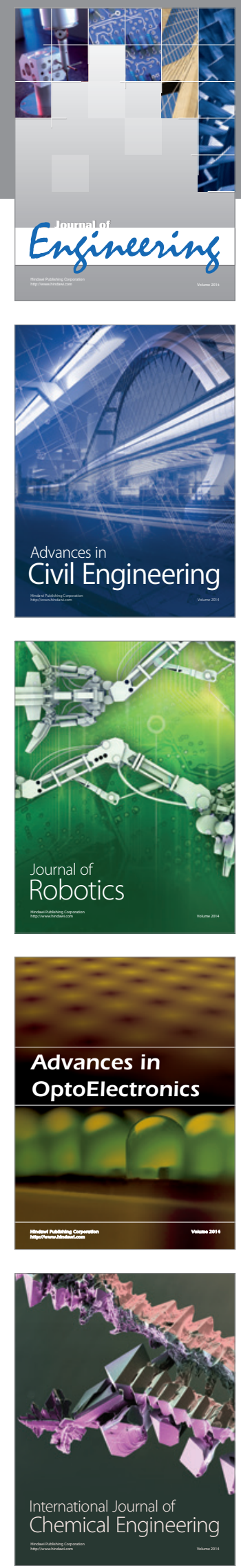

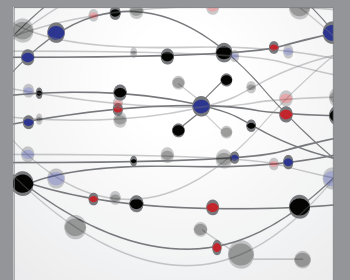

The Scientific World Journal
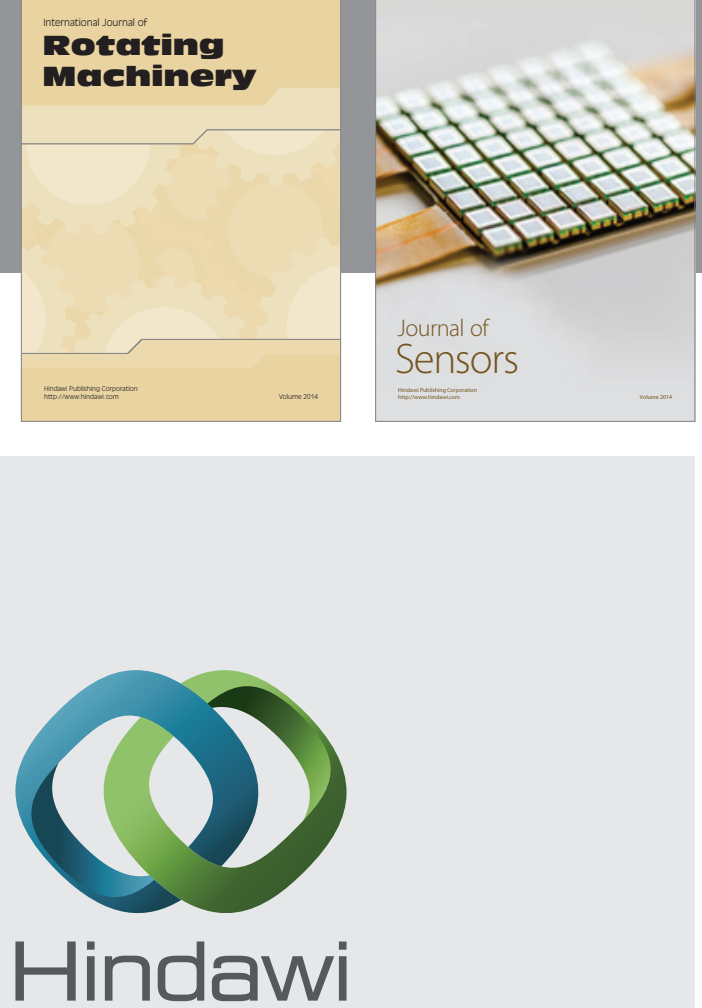

Submit your manuscripts at http://www.hindawi.com
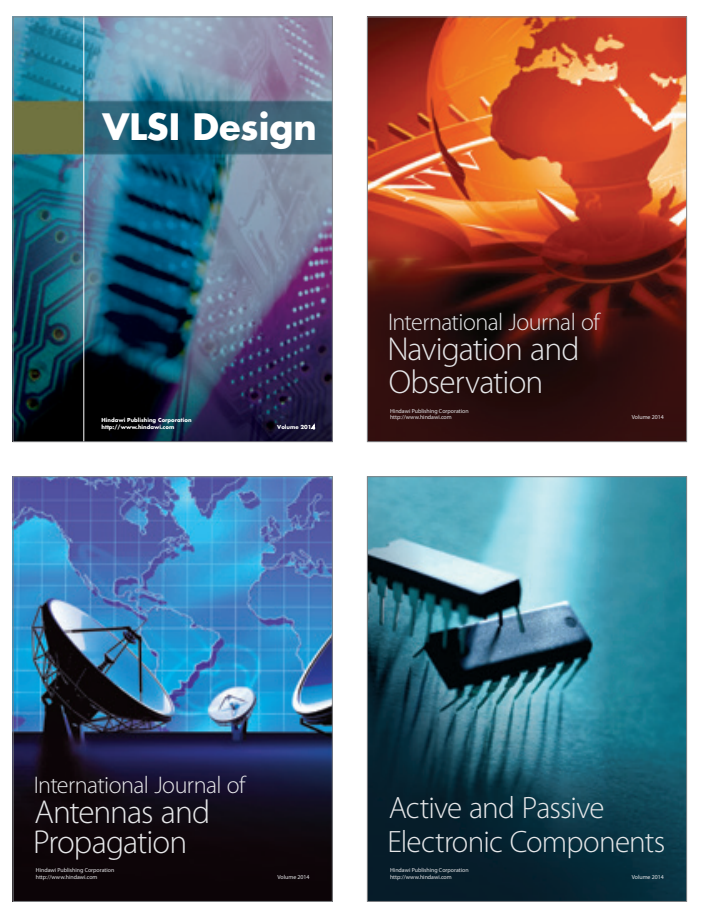
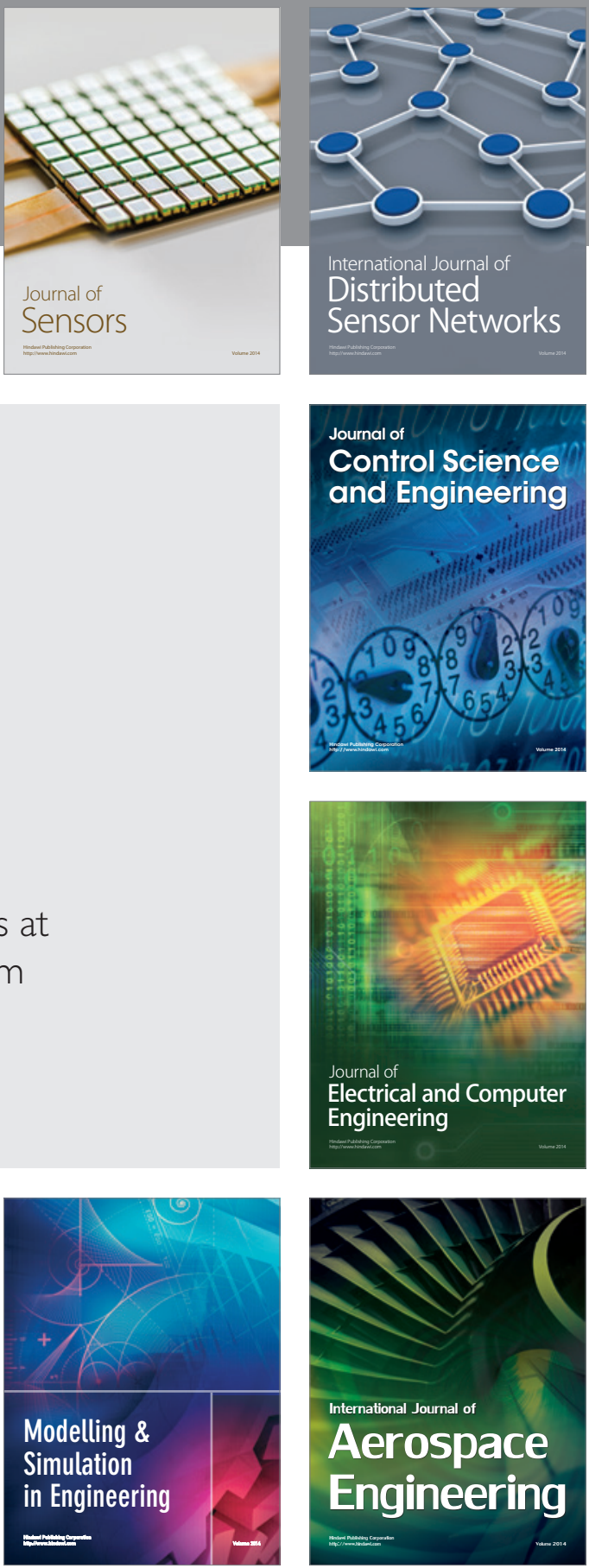

Journal of

Control Science

and Engineering
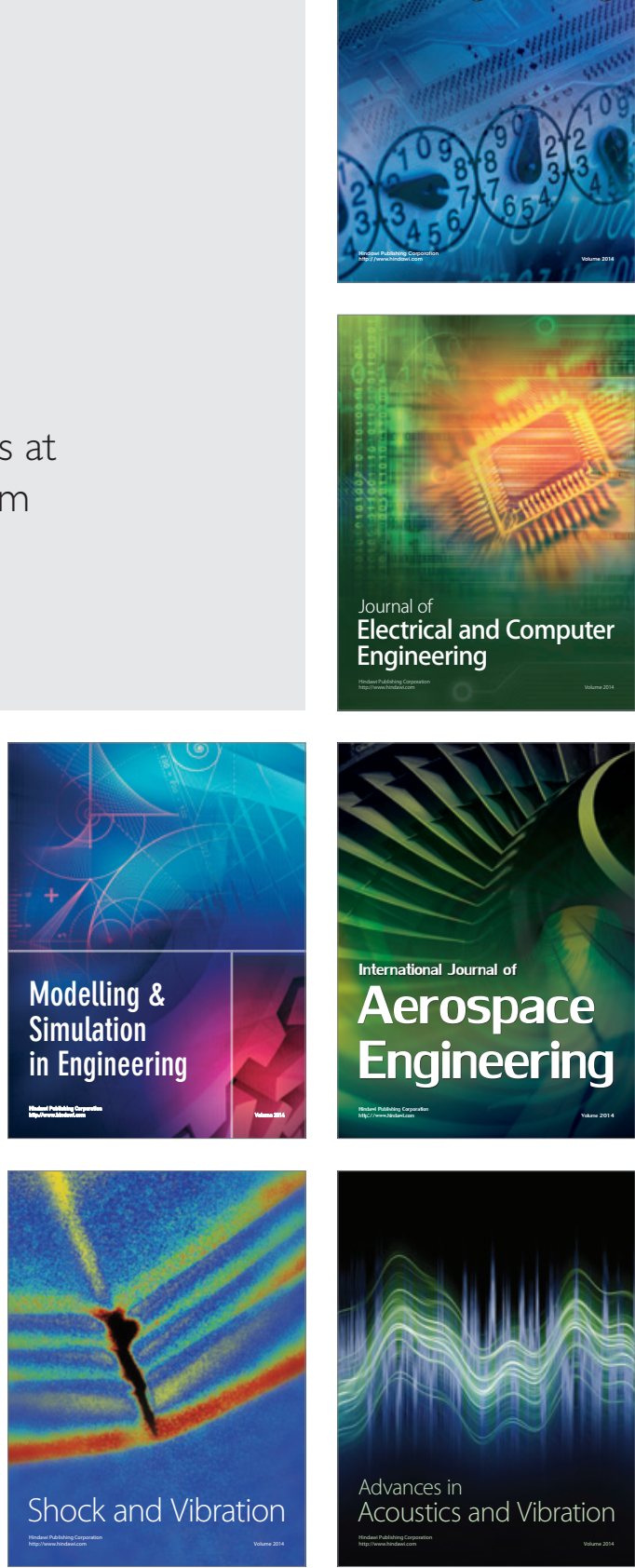